\title{
When Breadwinners fall Ill: Preliminary Findings from a Case Study in Bangladesh
}

\author{
Jane Pryer
}

\section{Introduction}

Most health and nutrition research conducted in developing countries has been primarily concerned with pregnant and nursing mothers and pre-school children, who have been identified as the most vulnerable members of society. A reflection of this concern is evident in the health and nutritional programmes of both international agencies and nongovernmental organisations (NGOs) which target their services almost exclusively to this group. One of the sources of vulnerability of women and children, particularly in the Bengali context, is their heavy dependence upon a male breadwinner. This article considers some preliminary findings on the implications for women and children of incapacitating illhealth amongst principal household earners. It is based upon fieldwork conducted by the author in an urban slum in Khulna, Bangladesh over a period of 18 months in 1984/85 and 1986/87, and is part of a broader study of the determinants of severe childhood malnutrition in the urban slum context [Pryer 1988].

A brief background to the study area is described in section 1, Section 2 examines the prevalence of sickness-induced loss of labour days amongst the study households and the associated loss of earnings. The next section goes on to investigate the role of adult earner morbidity in the impoverishment and malnourishment of households through the use of selected household profiles. The article concludes by discussing some of the policy implications of the case study findings.

\section{The Study Area}

Khulna is the second seaport and third city of Bangladesh, with a population in 1986 of around 750,000 . The city has a modest industrial base, and historically has been an important regional trading centre. Slums in Khulna have been estimated to contain 50 per cent of the city's population [World Bank 1981). Government health facilities in the city are extremely limited, being underfunded, understaffed and economically inaccessible to the urban poor. Cost is also a major constraint affecting the

For a more detailed discussion of the socio-economic and political structure of the slum see Pryer (1988). utilisation of private clinics by the poor. There are a few Mother and Child Health (MCH) projects and a child nutritional rehabilitation centre in the city which are aimed specifically at the urban poor and are run by NGOs. But the ability of these small projects to cope with the health needs of poor mothers and children of an entire city is very limited. Equivalent free health services for other family members are non-existent. In general the poor rely on private drug stores, staffed by unqualified traders, whose main motive is profit [Rolt 1985], and local homeopathic, religious and spiritual healers [Rahman 1984].

Medja Para (pseudonym) is an established inner-city slum with a population of 2,200. Environmental conditions are abhorrent, being overcrowded and insanitary. Nutritional and environmental diseases abound in these conditions. Cross-sectional surveys conducted in Medja Para between October 1986 and February 1987 indicate that the point prevalence of diarrhoea amongst children under five was $25 / 100$ child days: twice as high as the annual prevalence found in a rural study in Bangladesh, and three times higher than the rural prevalence at the same time of year [Black et al. 1982]. Nutritional status surveys conducted during the same time period show that seven per cent of under-fives were severely malnourished and 43 per cent moderately malnourished, using weight-for-age as an indicator. Relatively high rates of ill-health and malnutrition were not exclusively confined to young children - 43 per cent of mothers and 42 per cent of fathers had a $\mathrm{BMI}^{2}$ below 18 , which is considered indicative of adult malnutrition [Payne 1987].

Trade and the labour of household members were the most important sources of income in the slum. The slum labour market is highly differentiated by gender, reflecting the system of severe social control over women in Bangladesh [Kabeer 1988]. Employment opportunities for poor, uneducated women were scarce and restricted. Only 22 per cent of women worked, predominantly as domestic servants. But an increasing proportion of women workers were forced into black-market trading of Indian saris. Restricted female employment opportunities, compounded by low wage rates, had severe repercussions on poor households heavily dependent upon female labour

${ }^{2}$ BMI or Body Mass Index is an index of leanness or thinness which is used to assess nutritional status in adults. It is weight in $\mathrm{kgs}$, divided by height in metres squared. 
(e.g. when a male breadwinner falls ill). In contrast. the labour market for men was extremely diverse.

Despite an initial impression of homogeneity there was a high degree of inequality in the slum. Households were divided into four broad groups on the basis of total monthly income per consumption unit (CU):

^ The richest income quartile (Q1) relied predominantly upon trade for a living. their average monthly income being three times a locally constructed slum food poverty line. ${ }^{3}$

- The second richest income quartile (Q2) were much poorer than the Q1 households. Their average monthly income was only 40 per cent above the slum food poverty line and livelihood patterns were more heterogeneous.

- Households in the two poorest income quartiles (Q3 and Q4) were below the slum food poverty line. Eighty per cent relied on unskilled casual labour, the remainder were mainly petty traders and hawkers. This group is characterised by a low asset base. relatively high levels of female and child labour participation, a high percentage of income being devoted to food, and high levels of consumption

\footnotetext{
3 The slum food poverty line was constructed by the author and was based upon a weighted basket of the most commonly purchased and consumed foods by the slum households in 1986. It comprised $2800 \mathrm{Kcals}$ per adult male equivalent consumption u nit and cost 319 Taka/CU/month in December 1986.
}

indebtedness. A higher proportion of households in this group paid interest on loans at higher rates of interest.

\section{The Prevalence of Work-disabling Morbidity amongst Household Earners}

Results from a survey of 208 households ${ }^{4}$ show that nearly a quarter lost labour days due to an illness or accident in the month prior to interview. The average number of labour days lost due to ill-health in these households was 10 days/month. In 80 per cent of cases the incapacited earner was the male household head. Only rarely in three households (one per cent of the total), were labour days lost by household earners because another, dependent. household member was sick. This was probably because women's labour participation was low, and the sick dependents were usually either women themselves or were cared for by women. Total labour days lost due to illness in men as a proportion of total labour days worked by men in the whole sample was calculated as eight per cent. This is substantially higher than the reported Indian urban average of six per cent for male casual workers aged 15-55 in 1977-78 [Lipton 1983].

There were marked income quartile trends in the proportion of households with incapacited earners

${ }^{4}$ The cross-sectional survey was conducted between October 1986 and February 1987, covered all households living within the slum who had at least one child under five years at the time.

\section{Table 1}

Household Labour Days and Income Foregone due to Illness in Household Earners in Month Prior to Interview by Income Quartile

\begin{tabular}{|c|c|c|c|c|}
\hline & $\begin{array}{c}\text { Richest } \\
\text { Income } \\
Q 1 \\
(n=52)\end{array}$ & $\begin{array}{c}\text { Income } \\
Q^{2} \\
(n=52)\end{array}$ & $\begin{array}{c}\text { Income } \\
\text { Q3 } \\
(n=52)\end{array}$ & $\begin{array}{c}\text { Poorest } \\
\text { Income } \\
\stackrel{Q}{4}^{4} \\
(n 2)\end{array}$ \\
\hline $\begin{array}{l}\text { No. and } \% \text { of households with an } \\
\text { earner who has lost labour-days in } \\
\text { month prior to interview. }\end{array}$ & $\begin{array}{c}3 \\
(5.8 \%)\end{array}$ & $\begin{array}{c}7 \\
(13.5 \%)\end{array}$ & $\begin{array}{c}17 \\
(32.7 \%)\end{array}$ & $\begin{array}{c}22 \\
(42.3 \%)\end{array}$ \\
\hline $\begin{array}{l}\text { Mean No. of labour-days lost in } \\
\text { previous months due to illness in } \\
\text { affected households. }\end{array}$ & $\begin{array}{c}3.3 \\
(\mathrm{sd}=2.1)\end{array}$ & $(\mathrm{sd} \stackrel{7.14}{=} 10.2)$ & $\begin{array}{c}11.35 \\
(\mathrm{sd}=9.26)\end{array}$ & $\begin{array}{c}12.1 \\
(\mathrm{sd}=10.5)\end{array}$ \\
\hline $\begin{array}{l}\text { Mean income foregone in month prior } \\
\text { to interview due to incapacitation from } \\
\text { work in affected households (Taka)* }\end{array}$ & $\begin{array}{c}296 \\
(\mathbf{s d}=209)\end{array}$ & $(s d=97)$ & $\begin{array}{c}323 \\
(\mathrm{sd}=305)\end{array}$ & $\begin{array}{c}463 \\
(\mathrm{sd}=\end{array}$ \\
\hline $\begin{array}{l}\text { Income foregone due to illness as a \% } \\
\text { of all income earned in previous month } \\
\text { in affected households. }\end{array}$ & $\begin{array}{c}14 \% \\
(\mathrm{sd}=8.9)\end{array}$ & $\begin{array}{c}6.4 \% \\
(\mathrm{sd}=7.1)\end{array}$ & $\begin{array}{c}27 \% \\
(\mathrm{sd}=26.8)\end{array}$ & $\begin{array}{c}74 \% \\
(\mathrm{sd}=124)\end{array}$ \\
\hline
\end{tabular}

\footnotetext{
* £l Sterling $=47$ Taka in late 1986
} 
(Table 1). In total, 42 per cent of the poorest (Q4) households lost on average 12 labour days a month due to illness of one or more earners. In contrast only six per cent of the richest (Q1) households had lost labour days due to ill-health in the month prior to interview, and the average number of days lost due to illness in affected households was only three a month; no QI household lost more than five labour days a month. Incapacitation due to illness represented substantial losses of earnings in affected households and was disproportionately borne by the poorest. Furthermore, the majority of illnesses suffered by Q4 incapacitated earners were either chronic ( 60 per cent of cases including TB, chest and stomach pains and asthma), or due to work-related accidents ( 20 per cent of cases - burns, cuts and fractures). A similar pattern was seen amongst the Q3 households. In Q 1 incapacitation due to illness was primarily caused by acute illnesses (diarrhoea or headaches).

Income lost due to illness or accidents was not always directly proportional to the number of days that the earner was unable to work. In the poorest Q4, income lost per day incapacitated was higher than in Q2 and Q3. This is due to a combination of factors. Firstly, the physical presence of Q4 labourers is required to earn an income, whereas in some of the relatively richer trading households in Q2 other household members or relatives could be substituted (e.g. to run the family business) during short periods of illness. Secondly, one incapacitated earner in Q2 was a 'formal sector' worker, who was entitled to sickness benefit, resulting in no loss of income (at least in the short-run). Finally, three incapacitated earners (two in Q3 and one in Q4) were members of small labour groups which ran a type of health insurance for their members. The schemes were organised so that the day's earnings of the group as a whole were divided by one more than the number of members working on any one day. The extra wage saved was used to pay members during periods of illness at half their usual daily wage. But the vast majority (92 per cent) of households with sick earners did not receive any form of health insurance. In Q4 in particular the burden of lost earnings was borne directly by the household

Such substantial losses of earnings place poor households at risk of hunger and malnourishment, especially if the period of incapacitation is prolonged. Preliminary analyses of the association between incapacitation from employment at the household level and severe malnutrition in pre-school children revealed a strong association, which is highly statistically significant $(p=01$, refer to Table 2$)$. The relative risk of a severely malnourished child coming from a household with an incapacitated earner was two and a half times greater than from households without an incapacitated earner. It is also striking that 40 per cent of severely malnourished children in the slum came from households with incapacitated earners.

\section{The Role of III-health in Household Impoverishment and Malnourishment}

In this section the role of adult morbidity in the impoverishment and malnourishment of those households with severely weight-for-age malnourished children will be investigated through the use of household profiles. Describing the impact of adult ill-health in these households should lead to a greater understanding of the mechanisms involved and hence the types of policies most likely to alleviate the crisis.

The profile households included all households living in the slum which contained both a severely malnourished pre-school child and an incapacitated earner $(n=7)$. As the households had been interviewed during a previous period of field-work in the slum, an assessment could be made of the impact of incapacitating ill-health over the two-year period.

The characteristics of the profile households together with their responses to ill-health are summarised below. One illustrative household profile is also developed.

\section{(a) The Seven Profile Households}

\section{Type and Duration of Incapacitating Illness}

All of the incapacited earners in the seven profile households had been principal earners and were household heads. Six were male and one female. Five of the seven sick earners were chronically ill and weak. They suffered from either stomach pains ('gastric'), or chest pains and breathing difficulties ('hapicash'). They had been intermittently incapacitated from wage work over the two-year period, and typically were unable to work for 10 days per month due to ill-health. But one household earner was unable to work for 25 days per month; and another, the female household head, could only afford to forego employment for two to three days every other month, despite her extremely poor health and nutritional status.

The last two sick principal household earners had only recently been incapacitated from wage work. One, a washerman in a laundry, suffered from abcesses on his hands and had been unable to work for six weeks prior to our interview in 1986. The other suffered an accident at work and had been off work for two months in late 1986.

\section{Household Composition}

Three of the profile households were nuclear families, three were extended households and one was a household headed by a widow - a distribution which is similar to the slum as a whole. The average household size was 6.9 (range 5-10) - above the slum average of 5.9 . 


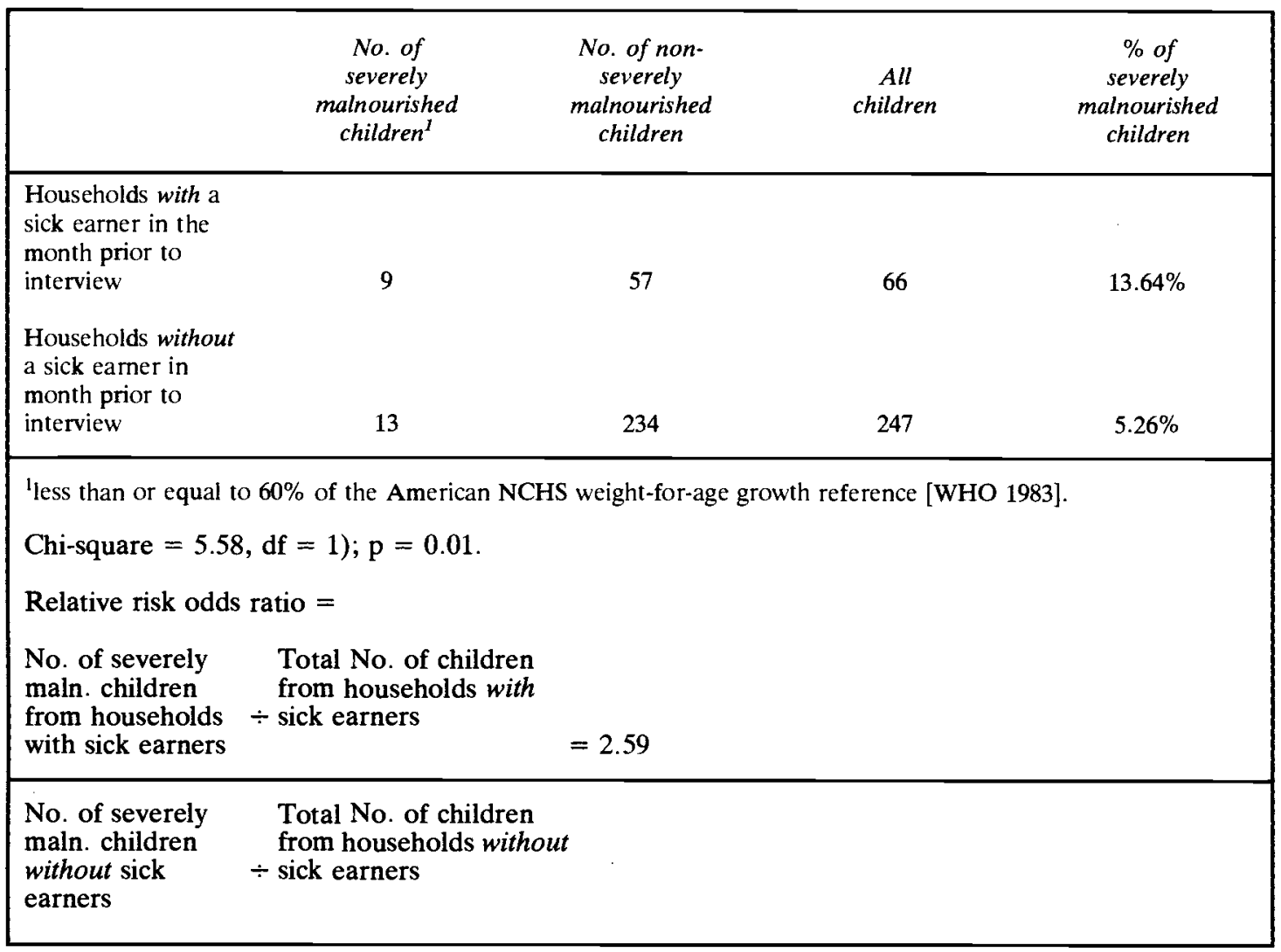

\section{Household Labour Participation and Pattern of Livelihood}

All the profile households were totally dependent for their livelihood upon the labour of household members. In 1984 there was on average one earner for 2.5 dependents in the five chronically incapacitated households, a dependency ratio which is slightly below the slum average. By 1986 the dependency ratio had decreased further from 2.5 to 1.3 in these households, whereas in the two more recently incapacitated households the dependency ratio had increased over the two-year period from 2.5 to 6.5. The lon dependency ratios in the chronically incapacitated households were due to higher levels of labour participation, particularly amongst women and children. Interestingly, this trend of decreasing dependency ratios over time in households where principal earners suffered prolonged incapacitation from wage work is the opposite to that found by Evans in his study of the impact of river blindness on rural households in Guinea [see Evans' article in this

\section{Bulletin].}

In 1986, labour participation rates amongst adult women and children were far higher in the five chronically incapacitated households than in the slum as a whole. Eighty per cent of women worked (four times the slum average) either as domestic servants or as black market petty traders. Forty per cent of both male and female children aged 5-15 years also contributed to the budget in these households. Boys worked as dependent scrap hawkers or as shop helpers, whereas girls were either domestic servants or begged and scavenged in the market place. In the two more recently ill households the pattern of labour participation was quite different. Here female members did not participate in the labour force. In the absence of the household head from wage work because of illness, it was only a teenage son who was economically active.

In 1984, two of the chronically incapacitated households had owned either productive or non- 
productive assets of financial value. The remaining households were virtually assetless and hence vulnerable to any crises. The types of assets owned included: working capital and tools for trade. marriage gold, or a few consumer durables (such as a radio or watch). By 1986, all households were virtually assetless. During the two-year period, the assets had been sold to richer slum tenants or to traders at values below the market rate, primarily to finance medical treatment of the chronically incapacitated houschold earner.

\section{Direct Costs of incapacitating Ill-health amongst Household Earners}

The estimated costs of medical expenditure for the incapacitated earners over the two-year period were much higher amongst those households who had both been incapacitated for prolonged periods and had originally owned either productive or non-productive assets of value in 1984. In all such households, the cost of medical expenditure was borne by the sale of assets. As soon as the receipts from the sale of the last asset had been spent. all further costly medical expenditure ceased.

In the remaining chronically ill households that were already assetless in 1984, medical expenditure was far lower over the two-year period. In cont rast to the large consumption loans that many of these households had slowly accumulated over a long time period (discussed below), it was simply too difficult for them to obtain large enough loans at short notice to finance costly medical treatment. Medical expenditure, therefore, was spread in small amounts over a lon time. Typically, 5-10 Taka was spent at any one time on a few drugs (often paracetemol, vitamins or an incomplete course of antibiotics) on the advice of unqualified drug traders. Traditional and spiritual healers were also consulted by all chronically incapacitated households.

In the two more recently ill households no expenditure was incurred on medical treatment. In one case (the earner suffering from abcesses on his hands) this was because no medical treatment was sought; in the other, the costs of treatment (for resetting a fractured arm) were met by a labour group of which the household was a member.

An important point is that in all households the estimated value of total wages foregone due to incapacitation was greater than the estimated total cost of medical treatment over the two-year period. Amongst the chronically incapacitated households, estimates of the value of income foregone ranged from two to 11 times that of medical expenditure. In the recently incapacitated households, however, no medical expenditure was incurred, the direct cost of incapacitating ill-health being entirely attributable to income foregone.

\section{Forms of Direct Support}

None of the profile households were 'formal sector' workers with entitlements to sickness benefit. However, one had been a member of a group of casual mill labourers who ran an informal insurance scheme for their members. He suffered from an accidental injury at work and received financial support at the rate of 50 per cent of his normal daily wage and the costs of medical treatment. The other six households, like the majority of slum households, did not receive any form of health insurance.

\section{Household Viability and Coping Strategies}

In 1984 six of the seven profile houscholds had monthly incomes below the slum food poverty line (SPL). By 1986 all were below the SPL, and monetary poverty had also intensified. In 1984, household income was on average 85 per cent of the SPL, but by 1986 this had declined to 73 percent, indicating that all houscholds were at risk of being unable to purchase enough food to fulfil nutritional needs. Household responses to the intensification of monetary poverty associated with incapacitation of a principal earner from wage work varied in their range and intensity, as shown in Table 3 and discussed below.

\section{Table 3 Responses of Profile Households to Loss of Earnings Associated with Incapacitation of a Principal Earner}

\begin{tabular}{|lcc|}
\hline & $\begin{array}{c}\text { Intermittently } \\
\text { incapacitated } \\
\text { households } \\
(\mathrm{n}=5)\end{array}$ & $\begin{array}{c}\text { Recently } \\
\text { incapacitated } \\
\text { households } \\
(\mathrm{n}=2)\end{array}$ \\
\hline $\begin{array}{l}\text { Consumption } \\
\text { loans } \\
\begin{array}{l}\text { Neighbour } \\
\text { support }\end{array}\end{array}$ & $100 \%$ & $50 \%$ \\
$\begin{array}{l}\text { Extended } \\
\text { family support } \\
\text { Decreased } \\
\text { food consumption } \\
\text { Collection } \\
\text { of wild food } \\
\text { Begging/ } \\
\text { scavenging } \\
\text { Participation of } \\
\text { women and/or } \\
\text { children in the } \\
\text { labour force }\end{array}$ & $100 \%$ & $50 \%$ \\
\hline
\end{tabular}


Six of the seven households were deeply indebted, with consumption loans averaging over four times their monthly income. This is more than five times the slum average, and twice as high as that found in the poorest income quartile. The only household that was not indebted for consumption needs was the recently incapacitated household, which was in receipt of informal health insurance. Loans had accumulated over a long time period and were obtained from a wide range of informal sources, at differing rates of interest (up to 30 per cent per month). In both absolute and relative terms the chronically incapacitated households were the most deeply indebted, with consumption loans averaging over 500 per cent of monthly income, whilst the recently incapacitated were the least indebted ( 154 per cent of monthly income).

As discussed above, an attempt to increase household income by entering women and/or children into the labour force was a common response in all chronically ill households, but not in those where earners had been recently ill. Slum neighbours were a constant source of support to most profile households in various ways including emotional support, helping to find jobs for women and children, occasionally donating or lending food and also sometimes in child-care. Finally, collection of wild food (water hyacinth which grows on ponds and rivers) and begging/scavenging in the market place were only resorted to by the chronically incapacitated. Despite the responses described, all hou seholds were forced to reduce the number of meals eaten daily. In the recently incapacitated households, two meals instead of three were usually consumed. In the chronically incapacitated households, the number of meals eaten was more irregular; occasionally only one meal was eaten, and not infrequently even this was foregone during periods of acute financial distress.

\section{Process and Onset of Malnutrition in the Household}

In 1986, it was not only pre-school children, but the majority of household members who were malnourished in these profile households. ${ }^{5}$ The incapacitated earners were particularly so; their BMI was on average only 16.9 (range 15.4-18.5), which compares with an average BMI of 19 for adult men in the slum as a whole.

A comparison of the household nutritional status profiles over the two-year period suggests that apart from the incapacitated earner, it was women and children who were the first to become malnourished.

\footnotetext{
${ }^{5}$ For the purpose of classifying current malnutrition at a household level the following nutritional indices and cut-offs were used for adult and child members. In adults BMI was used as a nutritional indicator and a cut-off of 18.5 was taken as indicative of current malnutrition. In children weight-for-height was used and 90 per cent of the American NCHS weight-for-height growth reference was taken as a cut-off; for further discussion see Dugdale (1985) and Payne (1987).
}

The BMI of the wives of the incapacitated earners was only 16.8 in 1986 , despite the fact that three of them were in the last trimester of pregnancy. As the process of impoverishment intensified, so too did the prevalence and intensity of malnutrition amongst all the household members. In 1986 three households had all members malnourished and in another three it wals only a teenage earner (usually male) who was spared. There was only one household where malnutrition was confined to children under five. This was the recently incapacitated household which was in receipt of informal health insurance.

In the seven profile households, nine children under five were severely malnourished. An examination of their nutrition and morbidity histories revealed that eight had been frequently ill and had either hovered around or remained within the severe malnutrition category for the entire two-year period. Only one child had recently plummeted into the severe malnutrition category, and this child came from a recently incapacitated household.

In all households, but particularly those with chronically sick earners, maternal time as well as intense financial poverty were major constraints on child-care and feeding. All of the mothers were malnourished, and were themselves either chronically ill and/or in the last trimester of pregnancy. If they were not working outside the household in an attempt to contribute to the household budget, they were fully occupied in the care of their husbands and in other domestic responsibilities. Emotional distress accompanied financial distress in all households. Usually other child caretakers were not available because older children in these households were working.

Most of the severely malnourished children had at some point over the two-year period, been referred to a Nutritional Rehabilitation Centre (NRU), by an NGO which ran a $\mathrm{MCH}$ project in the slum. The NGOs policy was that the child's mother should accompany the child to the NRU, as health and nutrition education of the mother was seen as an important part of the rehabilitation process. Only two attended until the child had at least gained some weight. Two months after discharge from the NRU however, the nutritional status of one of these children had deteriorated to previous levels. The other households either refused, or prematurely withdrew their child from the NRU; no household member could be spared to accompany the child, due to work or domestic responsibilities. ${ }^{6}$

\footnotetext{
The problem of non-attendance of severely malnourished children at nutritional rehabilitation centres due to time constraints of women is not specific to Khulna, but has been reported in other contexts. For an example in urban slums in Chimbote. Peru, see Pryer and Crook (1988).
} 


\section{(b) Household Profile}

Abdullah, aged about 50 , lives with his wife Hasna, aged about 35 , and their four daughters aged 18, 15,10 and 55 months. In December 1986 there were three earners to three dependents. The 15-year-old daughter worked as a domestic servant, and the ten-year-old scavenged in the market place for broken rice. Abdullah was chronically ill with severe chest and stomach pains. He was only able to work at home for a few hours on five or six days a month, weaving fishing nets. All household members were malnourished, and household income was only 30 per cent of the slum poverty line. They owned minimal household and productive assets and were deeply indebted, with loans amounting to over nine times their monthly income.

\section{Household History: the Role of Illness in the Process of Impoverishment}

Abdullah was born in the village of Pakhimara in Khula district. His paternal grandfather was originally a large farmer, but his land was gradually washed away by the river Shesbati. The patriline were rendered landless and Abdullah's father and grandfather worked as woodcutters in the Sunderban forests. Abdullah was the third of his parents' surviving children. His father's income was insufficient to meet household needs, so at the age of I I Abdullah was sent to an uncle in Khulna to work as an unskilled labourer, remitting his wage to the home village. Six or seven years later his father died from protracted diarrhoea, and that had severe financial repercussions for the family. Abdullah's mother had sold all the family possessions to pay for her husband's treatment, and they were also deeply indebted. It was a time of crop failure and hardship in the village. The family responded by selling their plot of house land and migrated to kin in India, returning four or five years later when the food crisis had subsided.

At the age of 27 or 28 Abdullah married Hasna. Two daughters were born, and then in 1968, Abdullah became partially paralysed. Over a period of six months Hasna sold her marriage gold, her husband's tools and their household possessions to finance treatment by a series of religious and homepathic healers. They were also deeply in debt. But Abdullah did not recover. Unable to survive in the village they sold the last of their household utensils and even the materials with which their house was constructed, and migrated to Khulna in the hope of survival and treatment. There they lived in a squatter settlement and survived during the first year by Hasna's begging with her younger, apparently undernourished child, who subsequently died. During this time Abdullah was treated by a homeopath and his paralysis was so far reduced that he was able to start working part-time in the wood depot of a Bihari who had given alms regularly to Hasna.

During the liberation war of Bangladesh in 1971 they went to their home village for safety and food. When they returned to K hula, the Bihari for whom Abdulla had worked had been killed and his depot looted. For the next year Abdullah did a variety of casuai jobs. In 1973-74 he started dealing in black-market wheat, which at that time had a good market, and the housel.old entered a phase of accumulation. In three or four years his business grew to a working capital of Taka 10,000. But in 1976-77 there was a dramatic decline in the black market supply of wheat. He spent Taka 2,000 on consumption (to cover the short-fall in income) and Taka 4,000 to treal Hasna, who was severely ill with her seventh pregnancy and later miscarried. In addition, Taka 3,000 was stolen from their home, Abdullah was forced to close his wheat business and did a variety of casual jobs. His worsening health meant that he could only work for at most 15 days per month. In 1980 Abdullah was totally incapacitated from wage work for a period of four months. Remaining assets, primarily consumer durables and gold (totalling Taka 6,000) accumulated during 1973-77, were sold to meet consumption needs and to finance medical treatment for Abdullah. At that time Hasna started working as a servant but she later ceased working on the birth of her youngest daughter, and her third daughter (then aged 10 years) took her place.

On our first visit in June 1984, the household was virtually assetless and under severe economic strain, Abdullah, due to his ill-health, was only able to work 15 days a month as a fisherman. His 12-year-old daughter worked in the food market as a servant and her eight-year-old sister accompanied her and collected fallen and broken rice from the stalls. Monthly income in cash and kind amounted to only 40 per cent of the slum poverty line, Abdullah could not afford to consult a medical practitioner. Rather, he regularly visited various drug stores and on the advice of traders purchased paracetemol tablets, to ease his stomach and chest pains, and also vitamin tablets. He also consulted various homeopathic and spiritual healers. Outstanding credit at three drug stores totalled Taka 1,100 (twice the household monthly income). They also owned Taka 500 to two food shops, Taka 250 to various slum neighbours and Taka 1,000 to a slum income generating scheme, which they had used for consumption. The family survived by cutting back on food consumption, which included fasting for two to three days per month. Abdullah, Hasna and the two youngest daughters were malnourished. The youngest child had been referred to the NRU, but the mother refused due to domestic responsibilities.

In mid-1984, Hasna responded to the crisis by entering the Indian sari black-market, a trade which, despite its 
risks. had become incrcasingly common amongst slum wom $\bullet$. Slum women considered it to be the only economic option available to them (apart from prostitution) where potential earnings could be equivalent to mens. Hasna borrowed Taka 1.000 from three richer slum women at 10 per cent monthly interest and purchased small consignments of saris at the Indian border three-four times weckly. By December 1984. Abdullah was incapacitated from wage work for 25 days per month. However. due to Hasna's trading. household monthly income had doubled (compared to Junc). Hasna knew the risks of this type of illegal trading: four of her women friends had been detained by the police. Indecd. saris worth Taka 750 had been confiscated from Hasna at the border two months previously. which represented all her working capital.

From 1985 onwards. Abdullah s chest pains intensified and he became totally incapacitated from wage work. For six months he was confined to bed. but from June 1985 onwards he was able to work for five to six days per month at home weaving fishing nets. His poor health meant that it took him four-five months to complete a net. and the total profit received in this time was only sufficient to meet household needs for seven to 10 days. The household relied primarily upon Hasna s illegal trading as their main survival strategy. But since 1984. Hasna had consignments of saris confiscated at the border ten times and had also been severely physically assaulted. The regular confiscation of working capital meant that potential earnings were never realised and the family were constantly struggling to survive. In September 1986 new legislation was introduced by the Bangladesh government which made it illegal not only to smuggle saris across the border. but also to sell them with in Bangladesh. This resulted in even tighter border controls. In October 1986 Hasna was seven months pregnant. her last consignment of saris were again confiscated and she was severely beaten. Hasna has since been unable to trade. Monthly income in October through December 1986 was 30 per cent of the slum poverty line. and outstanding loans for medicines. consumption and trade increased over the two-year period to Taka 4.500 (900 per cent of monthly income). By December 1986 all household members were malnourished.

In the above profile ill-health was an initiating factor to the further entrenchment of poverty over two generations. By 1984 when this household were first contacted." available assets had already been sold to finance medical expenditure and consumption and the household was vulnerable to the costs of further crises. Levels of child labour participation and consumption indebtedness were already high. and nutritional needs jeopardised. Over the two-year observation period the household responded to further incapacitating illhealth by relatively low levels of medical expenditure financed by further eredit and loans. by increasing fomale and child labour participation and incrcasing consumption indebtedness to feed the family. These responses are typical of many chronically inca pacitated households. although in two cases assets were also sold during the two-year period to finance medical treatment. But the profiles also clearly illustrate the restricted economic options available to uneducated slum women faced with an incapacitatcd male carner. The low returns from domestic service (the main economic option available to uneducated slum women) forced Hasna into illegal trading in an attempt to feed her family. but the promise of income levels equivalent to men's was never realised.

\section{Conclusions and Policy Implications}

The prevalence of sickness-induced loss of employment was found to be high in the study population. represented substantial losses of earnings and was disproportionately borne by the poorest households. Furthermore. the illnesses suffered by the incapacitated earners in the poorest income quartiles were chronic in nature. In the slum as a whole. the relative risk of a severely malnourished child coming from a household with an incapacitated earner was two and a half times greater than from households without an incapacitated earner. A closer examination of households with both severely malnourished children and incapacitated earners revealed that it was not only young children. but most members who were malnourished in these households.

The policy implications of the findings of this urban slum case study for NGOs and international agencies mandated either to improve child health or to enhance basic needs entitlements relate firstly to the reorientation of health programmes to cover all household members. rather than just mothers and children. Secondly. if nutritional rehabilitation centres are to be part of an overall health programme. consideration must be given to the time constraints faced by child care-takers in severely malnourished households. Thirdly. emphasis should be placed on community-based insurance and credit schemes to ease the financial burden and distress incurred following sickness-induced loss of income. Finally, this case study highlights the heavy dependence of women and children on the health and earning capacity of male breadwinners. and the limited economic options available to slum women faced with an incapacitated male earner. This reinforces the case for programmes to loosen the severe constraints faced by women in Bangladesh. and to support greater female independence.

\section{References}

Black. R. E.. Brown. K. H.. Becker. S. and Yunus. M.. 1982. 'Longitudinal studies of infectious diseases and physical 
growth of children in rural Bangladesh'. American Journal of Clinical Nurrition vol 115 no 3. pp 305-14

Dugdale, A. E., 1985, 'Family anthropometry: a new st rategy for determining community nutrition' lancel 672, 21 st Sept.

Kabeer. N.. 1988. 'Subordination and struggle: women in Bangladesh' Nell lefi Review no 168, pp 95-121

Lipton. M., 1983. 'Labour and poverty', World Bank Sraff Working Paper, World Bank, Washington D.C.

Payne. P., 1987. 'Undernutrition: measurement and implications". Paper presented at WIDER conference on Poverty. Undernutrition and Living Standards. Helsinki 27-31 July

Pryer, J., 1988, 'Socio-economic aspects of Malnutrition and ill-health in an urban slum in Bangladesin', $O D A$ Rescarch Reporl R4296. London

-and Crook. N., 1988. 'Cirics of Hunger: Urban Malnurrition in. Developing Counrics'. Oxfam Press. Oxford

Rahman. M. H., 1984, 'Base line survey of Shaik Para by Lane Bustee, Khula' UNICEF. Dhaka. Bangladesh (mimeo)

$\cdot$

Rolt, F., 1985. 'Pills Policies and Profirs' War on Want. London

World Bank, 1981. 'Bangladesh: Urban sector memorandum". World Bank. Dhaka (mimeo)

World Health Organisation. 1983, Mcasuring change in nutritional staus'. WHO. Rome 